\title{
PSYCHOLOGICAL STRESS AMONG FAMILY PRACTICE PATIENTS VISITING A TEACHING HOSPITAL IN KARACHI
}

\author{
Waris Qidwai and Malika Kassamali
}

\begin{abstract}
OBJECTIVE: To study psychological stress among family practice patients to highlight its importance.

DESIGN: A cross sectional study.

SETTING: Family Practice Center of Aga Khan University Hospital, Karachi - Pakistan, in July 2003.

PATIENTS AND METHODS: Family practice patients were interviewed without using any systematic randomization. A questionnaire was developed that included data on demographic profile of the patient and questions on patient perceptions whether they were in stress or not, the degree of stress if perceived to be present and its causes including need to seek medical help. They were simultaneously administered a stress screening questionnaire that showed whether they were under stress or not including the degree of stress if present. The questionnaire was administered by an elective student working at the department of family medicine. Ethical requirements including the administration of written informed consent and the provision of confidentiality were ensured. SPSS computer software was used for data management.

RESULTS: Total 100 patients were interviewed, of which $\mathbf{5 1}$ were females. According to the screening questionnaire $04(04 \%), 33(33 \%)$ and 63(63\%) respondents were under "severe", "moderate" and "no particular stress" respectively. According to patient perception, 03(3\%), 10 $(10 \%)$ and $17(17 \%)$ respondents reported having severe, moderate and mild stress respectively. Stress was mostly related to work (40\%) and domestic issues (20\%).

CONCLUSION: It is important to screen patients visiting family physicians for underlying stress. Patient perceptions of stress matched the screening tool and therefore asking a simple question that patients are stressed may be adequate.
\end{abstract}

KEY WORDS: Psychological Stress. Family Practice. General practice.

\section{INTRODUCTION}

Stress is universal and affects all human beings. Stress wherein emotional factors predominate is regarded as "psychological stress". ${ }^{1}$ Psychological stress is known to be the cause for several ailments and reduces the quality of life. It is widely believed to be an important determinant of heart disease ${ }^{2-5}$, is considered a factor in the development of generalized anxiety disorder ${ }^{6}$, depression ${ }^{7}$ and in the alteration of immune response in asthma. ${ }^{8}$ Psychological stress has been implicated from its possible role in causation of peptic ulcer ${ }^{9}$, to reduced survival rates in patients with cancer. ${ }^{10}$ It is reported that $43 \%$ of all adults suffer adverse health effects from stress, while 75 to $90 \%$ of all physician office visits are for stress-related ailments and complaints. ${ }^{11}$
American industry loses more than $\$ 300$ billion annually or $\$ 7,500$ per worker per year due to stress among workers. ${ }^{11}$ Interventions are required at the level of family doctors to tackle stress among patients. We require more local data on the prevalence of stress among patients visiting family physicians. A need exists to study stress among family practice patients to investigate the prevalence of stress among them, the levels of stress if present as well as the factors leading to it. Piloting of such a survey will lead to larger studies that may help interventions at the level of family physicians to tackle the stress among patients.

\section{PATIENTS AND METHODS}

This study was a questionnaire based cross sectional survey. It was conducted at the Family Practice 
Center, Aga Khan University Hospital, Karachi, Pakistan in July 2003. Around 150 family practice patients are seen daily by twelve family physicians at the center. Patients present with primary care level problems at the center. Questionnaire was developed by the study investigators and was administered in English and Urdu, depending on patient's comfort ability. The questionnaire included data on demographic profile of the patient including age, sex, marital status, education and occupation. The survey had two sections. First part was a screening questionnaire ${ }^{12}$ for stress. All questions were categorized under headlines of Always, Sometimes and Rarely with scores of 2, 1 and 0 respectively. Those who scored between 0 and 10 were termed as not particularly stressed, scorers between 11 and 20 were moderately stressed and those who scored between 21 and 30 were severely stressed. Second section of the questionnaire contained questions on whether patient himself/herself thought was under stress, level of stress if present and its source. The study investigator interviewed the patients and filled out the questionnaire. A pilot study was conducted before the start of the administration of the final questionnaire.

The questionnaire was administered in the waiting area outside the physician office, prior to the consultation. Patients interviewed were those who agreed to participate in the study. Since, we planned a descriptive study and did not intend to subject the data to statistical tests, sample size based on statistical calculations was not considered. Ethical requirements including the administration of written informed consent and the provision of confidentiality were ensured. We interviewed patients based on their availability and convenience. A systematic random selection of study subjects was not under taken. SPSS computer software was used for data management.

\section{RESULTS}

A total of 100 patients was interviewed. Among these, $51(51 \%)$ respondents were females, 61(61\%) were married, 62(62\%) had graduate or more education and $25(25 \%)$ were housewives (Table I). Results of the screening questionnaire indicated that $63(63 \%)$, $33(33 \%)$ and $04(04 \%)$ of the respondents "were not under stress", "were under moderate stress" and "severe stress" respectively. However, results to the second section of the questionnaire depicted that 58
(58\%), $30(30 \%)$ and $12(12 \%)$ of the respondents thought they "were not under stress", "were under stress" and "were not sure whether they were under stress or not" respectively (Table II). In comparison to screening questionnaire with four people being severely stressed, nine patients in the second part of the questionnaire thought they were under severe stress. Stress due to work related, domestic and financial reasons was noted in 40(40\%), 20(20\%) and 07(07\%) respondents respectively. Majority of the respondents (52\%) did not intend to seek help while those who did take help complained that they do not really feel satisfied through counseling. Of all the hundred patients interviewed, eleven thought that stress to an extent was healthy and improves thinking skills, prepares for future challenges and is part of human life cycle. Students regarded it as an alarm/warning for upcoming examinations and assignments. The remaining eightynine patients who thought of stress as being unhealthy concluded that it leads to diseases and other health disorders, diminishes the quality of life by reducing feelings of pleasure and accomplishment and relationships are often threatened, they lose concentration and are unable to pay proper attention to other important aspects in the life.

TABLE I:

DEMOGRAPHIC PROFILE OF THE PATIENTS $(n=100)$

\begin{tabular}{|l|c|}
\hline \multicolumn{1}{|c|}{ PARAMETER } & PERCENT \\
\hline Sex: & 49 \\
Males & \\
\hline Marital Status: & 61 \\
Married & \\
\hline Occupational Status: & \\
Housewife & 25 \\
Student & 26 \\
Professional & 35 \\
Self-employed & 13 \\
Others & 01 \\
\hline Educational Status: & \\
Secondary & 11 \\
Intermediate & 27 \\
Graduate & 54 \\
Post-Graduate & 08 \\
\hline
\end{tabular}


TABLE II:

PATIENT PERCEPTIONS REGARDING STRESS

\begin{tabular}{|l|c|}
\hline PERCEPTION PARAMETER & PERCENT \\
\hline People who think they are: & \\
Stressed & 30 \\
Not Stressed & 58 \\
Don't Know & 12 \\
\hline Areas of Stress: & \\
Domestic & 20 \\
Work Related & 40 \\
Financial & 6.66 \\
Health & 3.33 \\
Education & 3.33 \\
All Areas & 26.66 \\
\hline Level of Stress & \\
Mild & 17 \\
Moderate & 10 \\
Severe & 03 \\
\hline Intention to seek help & \\
Yes & 35 \\
No & 52 \\
Don't Know & 13 \\
\hline
\end{tabular}

\section{DISCUSSION}

This study reflects the pattern of stress among family practice patients and documents patient perceptions on their stress levels and its sources. Since, a limited number of patients were interviewed and without using systematic random method for patient selection, generalization of the study results cannot be recommended. The educational background was not uniformly distributed with a majority of graduates and the rest with at least secondary school education. Being well educated perhaps enhances one's capacity to cope with stressful situations in life without getting worked up while the stresses in this select group may be different from the rest of the population.

It is assumed that housewives have their own stresses and a quarter of the respondents were housewives in this study. Despite all the limitations, we have collected useful information that offers insight into the issue of stress among family practice patients with better education. We have been able to make point that a substantial number of family practice patients are under stress and they are either unaware of it or are not considering to seek medical help. The information we have gathered can be used to understand stress among family practice patients and its possible sources. It highlights the need to screen for stress among patients at the family physician level. With the help of screening questionnaire, we found a substan- tial $(37 \%)$ number of respondents under stress, which included four with severe stress. This is an alarming situation, which requires special attention. It is important to note that $30 \%$ respondents thought they were under stress which is similar to the number obtained through the screening questionnaire. This means that by asking patients whether they are under stress or not, can help us identify those who may require further questioning. The major areas identified as sources for stress included both work related $(40 \%)$ as well domestic (20\%), with a substantial number $(26 \%)$ reporting stress from all sources including finance. This information helps a physician to provide effective counseling, since the areas to focus become clear. The holistic approach of a family physician provides an excellent opportunity to not only pick up cases with psychological stress but to provide them care including appropriate referral in selected cases. Recent research conducted by the Health Enhancement Research Organization (HERO) in Birmingham, Alabama has shown that primary care patients receiving stress management interventions required fewer hospitalizations and emergency room visits. Conversely, the HERO study found that health care costs increased dramatically when stress and depression went untreated. The study included over 46,000 workers at several major U.S. companies. Results revealed that medical costs were $70 \%$ higher among individuals with untreated depression and $46 \%$ higher among individuals reporting uncontrolled and untreated stress. In fact, depression and stress were the primary predictors of total health care costs. ${ }^{13}$ Despite, claims to the contrary ${ }^{14}$, a lot of psychological morbidity in primary care is known to go unrecognized, undiagnosed and therefore untreated. ${ }^{15-17}$ This is, despite, claims that Primary Care Physicians provide psychological care to a substantial number of patients. A significant level of psychiatric morbidity is reported to be present in the developing world. ${ }^{18}$ High levels of stress among Pakistanis have also been identified through several studies. ${ }^{19-20}$ Hence, family physicians are the frontline healthcare providers and in frequent contact with these patients.

\section{CONCLUSION}

The presence of psychological stress is associated with increased morbidity and mortality. Family Physicians are frontline doctors who can help screen patients with significant levels of stress and offer them help. We strongly recommend further study on the issue in the community and with a larger sample size. Based on this study findings, we also strongly recommend that family physicians screen their patients for psychological stress. 


\section{REFERENCES}

1. National library of medicine. Psychological stress. 2004 [Online]. Available from: http:// www.ncbi.mlm.nih.gov/entrez/query.fcgi? $\mathrm{CMD}=$ search\&DB=mesh [cited August 2006].

2. Davison C, Smith GD, Frankel SJ. Lay epidemiology and the prevention paradox: the implications of the coronary candidate for health promotion. Sociol Health Illness. 1991; 13: 1-19.

3. Greenwood DC, Muir KR, Packham CJ, Madeley RJ. Coronary heart disease: a review of the role of psychosocial stress and social support. J Pub Health Med. 1996; 18: 221-31.

4. Hemingway $\mathrm{H}$, Marmot $\mathrm{M}$. Evidence based cardiology: psychosocial factors in the aetiology and prognosis of coronary heart disease: systematic review of prospective cohort studies. $\mathrm{Br}$ Med J. 1999; 318: 1460-67.

5. Ramachandruni S, Handberg E, Sheps DS. Acute and chronic psychological stress in coronary disease. Curr Opin Cardiol. 2004;19: 494-9.

6. Hale AS. ABC of mental health. Anxiety. Br Med J. 1997;314:1886-9.

7. Claes SJ. CRH, stress, and major depression: a psychobiological interplay. Vitam Horm. 2004; 69:117-50.

8. Chen E, Fisher EB, Bacharier LB, Strunk RC. Socioeconomic status, stress and immune markers in adolescents with asthma. Psychosom Med. 2003;65:984-92.

9. Levenstein S. Stress and peptic ulcer: life beyond Helicobacter. Br Med J. 1998;316:538-41.

10. Petticrew M, Bell R, Hunter D. Influence of psychological coping on survival and recurrence in people with cancer: systematic review. Br Med J. 2002;325:1066.
11. Miller LH, Smith AD. The stress solution. 2004 [Online]. Available from: http://helping.apa.org/ work/stress2.html [cited August 2006].

12. Firth S. A quick questionnaire on stress. 2004 [Online]. Available from: http://www.insightpsychology.co.uk/Stress.pdf [cited August 2006].

13. Mikail SF, McGrath P, Service J. Strengthening Primary care: The Contribution of the Science and Practice of Psychology. 2004[Online]. Available from: http://www.cpa.ca/primarycare-1.html [cited August 2006].

14. Olfson M, Weissman MM, Leon AC, Higgins ES, Barrett JE, Blacklow RS. Psychological management by family physicians. J Fam Pract. 1995;41:543-50.

15. Eisenberg L. Treating depression and anxiety in primary care. Closing the gap between knowledge and practice. N Engl J Med. 1992;326:1080-4.

16. Higgins ES. A review of unrecognized mental illness in primary care. Prevalence, natural history, and efforts to change the course. Arch Fam Med. 1994;3:908-17.

17. Mumford DB, Minhas FA, Akhtar I, Akhter S, Mubbashar $\mathrm{MH}$. Stress and psychiatric disorder in urban Rawalpindi. Community survey. Br J Psychiatry. 2000;177:557-62.

18. Sugar JA, Kleinman A, Eisenberg L. Psychiatric morbidity in developing countries and American psychiatry's role in international health. Hosp Community Psychiatry. 1992;43:355-60.

19. Mumford DB, Saeed K, Ahmad I, Latif S, Mubbashar $\mathrm{MH}$. Stress and psychiatric disorder in rural Punjab. A community survey. $\mathrm{Br} \mathrm{J}$ Psychiatry. $1997 ; 170: 473-8$.

20. Irfan N, Badar A. Top ten stressors in the hysterical subjects of Peshawar. J Ayub Med Coll Abbottabad. 2002;14:38-41.

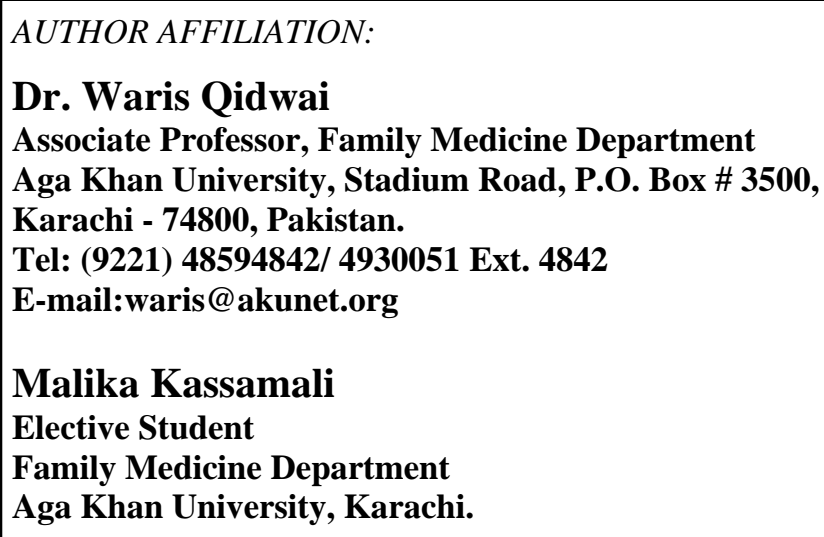

